\title{
Visual loss in an onchocerciasis endemic community in Sierra Leone
}

\author{
J A G Whitworth, C E Gilbert, D M Mabey, D Morgan, A Foster
}

\begin{abstract}
The visual acuities of 1625 individuals recruited to a community-based clinical trial of ivermectin in southern Sierra Leone were measured, and the prevalence of visual loss in this rural population where onchocerciasis is hyperendemic was determined. Ocular examination was performed before treatment to establish the cause of visual loss. Using WHO definitions, $1.3 \%$ were blind (less than $3 / 60$ in both eyes), $4.3 \%$ were visually impaired (between 6/24 and 3/60 in the better eye), and a further $3.4 \%$ were uniocularly blind (less than $3 / 60$ in one eye and better than $6 / 24$ in the other). Cataract and onchocerciasis were the major causes of visual loss in this population. More than half of the ocular morbidity was preventable or treatable by public health measures or basic curative medicine. These findings are discussed in the light of the available health and eye care services.

(Brf Ophthalmol 1993; 77: 30-32)
\end{abstract}

Sierra Leone is a small and well populated West African country. ${ }^{1}$ As elsewhere in Africa there are few ophthalmologists, with only four for four million people. Ophthalmic services are provided by four hospitals (two government and two voluntary agency) situated in the capital Freetown, Bo, and Lunsar. There is a national plan to develop eye care services and prevent blindness. A cadre of ophthalmic nurse practitioners has been established; so far 12 have been trained and a further 14 are in training.

Onchocerciasis, a chronic nematode parasitic infection that affects the eyes and skin, ${ }^{2}$ is endemic in most of Sierra Leone. ${ }^{3}$ The staff of the Medical Research Council (MRC) laboratory in Bo have been studying the effects of ivermectin on onchocerciasis in a double blind placebo controlled, community based study since $1987 .{ }^{4}$ Data collected at the outset of the study included visual acuity measurements and details of ocular examination. From these data we have determined the prevalence and causes of visual loss in the study population. This information will be useful in evaluating measures taken to combat onchocerciasis and in planning, instituting, and assessing ophthalmic services and prevention of blindness programmes.

\section{Subjects and methods}

Six adjacent villages were selected for the MRC ivermectin study in the Tabe river valley, $25 \mathrm{~km}$ north west of Bo. These villages were chosen because previous studies had shown that onchocerciasis was hyperendemic in that region. ${ }^{5}$ This is an area of mixed oil palm bush and secondary forest, the population are from the Mende tribe, and most are subsistence farmers. None of the villages had existing health care facilities and the nearest ophthalmic clinic was held in Bo once each month. The study population had limited access to this clinic because of the cost and scarcity of public transport. Traditional eye medicines are frequently used and couching is sometimes practised for advanced cataract.

Before the ivermectin trial a census was taken in each village and all individuals aged 1 year or older were invited to participate in the study. Pretreatment baseline data were then obtained from all participants including name and age, and skin snips were taken from both iliac crests to determine the prevalence and intensity of Onchocerca volvulus infection. Visual acuity was measured for each eye separately using an illiterate $\mathrm{E}$ chart. The visual status of individuals was determined according to the WHO classification, using the vision of the better eye:

blind: visual acuity less than $3 / 60$

visual impairment: visual acuity less than $6 / 18$ but better or equal to $3 / 60$

uniocular blindness: visual acuity less than $3 / 60$ in one eye and $6 / 18$ or better in the other

normal: no evidence of blindness or visual impairment

Visual loss encompasses blindness and visual impairment.

If the visual acuity was less than $6 / 18$ in either eye a basic eye examination (BEE) of both eyes was undertaken. In the BEE a torch and loupe were used to examine the anterior segment and a direct ophthalmoscope to examine the posterior chamber after pupillary dilatation with $1 \%$ tropicamide. An assessment was made of the main anatomical cause of visual loss and the likely aetiology in each case. Individuals in whom the cause could not be determined by a BEE underwent a special eye examination (SEE) by an ophthalmologist. In the SEE the anterior segment was examined using a Zeiss portable slitlamp with $\times 25$ magnification. Intraocular pressures (IOPs) were measured by hand-held applanation tonometry and gonioscopy performed on those with raised IOP and signs of onchocercal eye disease. The posterior segment was examined by direct and indirect ophthalmoscopy after pupillary dilatation. Data were recorded using a simplified version of the Eye Examination Record developed by the WHO Prevention of Blindness Programme. ${ }^{6}$

Visual field examinations and fluorescein angiography were not performed. All data were double entered into an IBM microcomputer and analysed using appropriate software. 


\section{Results}

A total of 1742 people were listed in the census and $1625(93 \%)$ attended the pretreatment survey. The prevalence of onchocerciasis was $65 \%$, with a geometric mean of 3.34 microfilariae per $\mathrm{mg}$ of skin. There were 225 children (all aged less than 13 years) unable to perform the illiterate $E$ visual acuity test. None of them were blind in both eyes, but it could not be determined accurately whether any of them had visual impairment or uniocular blindness. Therefore these 225 cases were included in the denominator for analyses of blindness but excluded for visual impairment and uniocular blindness. The prevalence of blindness was $1 \cdot 3 \%(21 / 1625,95 \%$ confidence limits: $0 \cdot 7-1 \cdot 9 \%$ ) and the prevalences of visual impairment and uniocular blindness were $4 \cdot 3 \%(60 / 1400,95 \%$ confidence limits: $3 \cdot 2-$ $5 \cdot 4 \%)$ and $3 \cdot 4 \%(48 / 1400,95 \%$ confidence limits: $2 \cdot 4-4 \cdot 4 \%)$ respectively. In all categories the prevalence increased with age (Table 1).

The causes of visual loss are shown in Table 2. Cataract was the second commonest cause of blindness and the commonest cause of visual impairment and unilateral blindness. (Cataract includes uncorrected aphakia and complications related to couching.) Overall, cataract was the cause of visual loss or uniocular blindness in $4 \cdot 5 \%$ of the study population.

Onchocerciasis was the commonest cause of blindness, the second most frequent cause of visual impairment, and accounted for $10 \%$ of unilateral blindness. Overall, onchocerciasis accounted for visual loss or uniocular blindness in $1.5 \%$ of the study population. Anterior segment disease: sclerosing keratitis (Fig 1A), chronic uveitis (Fig 1B), and secondary cataract caused as much visual loss as posterior segment disease (optic atrophy and chorioretinitis). However, in most cases visual loss was due to a combination of anterior and posterior segment changes, including secondary glaucoma.

Glaucoma was the cause of blindness or visual

Table 1 Visual acuities in a rural population in Sierra Leone

\begin{tabular}{lccccc}
\hline $\begin{array}{l}\text { Age } \\
\text { group } \\
\text { (years) }\end{array}$ & $\begin{array}{l}\text { Number } \\
\text { examined }\end{array}$ & $\begin{array}{l}\text { Not } \\
\text { assessed }\end{array}$ & Blindness & $\begin{array}{l}\text { Visual } \\
\text { impairment }\end{array}$ & $\begin{array}{l}\text { Uniocular } \\
\text { blindness }\end{array}$ \\
\hline $1-9$ & 168 & 223 & 0 & 0 & 0 \\
$10-19$ & 222 & 2 & 0 & 0 & $1(0 \cdot 5 \%)$ \\
$20-29$ & 227 & 0 & 0 & $1(0 \cdot 4 \%)$ & $3(1 \cdot 3 \%)$ \\
$30-39$ & 155 & 0 & 0 & 0 & $3(1.9 \%)$ \\
$40-49$ & 156 & 0 & $4(2 \cdot 6 \%)$ & $1(0 \cdot 6 \%)$ & $5(3 \cdot 2 \%)$ \\
$50-59$ & 169 & 0 & $2(1 \cdot 2 \%)$ & $5(3 \cdot 0 \%)$ & $11(6 \cdot 5 \%)$ \\
$60+$ & 303 & 0 & $15(5 \cdot 0 \%)$ & $53(17 \cdot 5 \%)$ & $25(8 \cdot 3 \%)$ \\
All ages & 1400 & 225 & $21(1 \cdot 3 \%)$ & $60(4 \cdot 3 \%)$ & $48(3 \cdot 4 \%)$ \\
\hline
\end{tabular}

- Defined as visual acuity worse than $3 / 60$ in the better eye, denominator 1625 .

"Acuity less than 6/18-3/60 in the better eye, denominator 1400 .

Acuity worse than $3 / 60$ in one eye and $6 / 18$ or better in the other, denominator 1400 .

Table 2 Causes of visual loss and uniocular blindness in a rural population in Sierra Leone

\begin{tabular}{lccc}
\hline Cause & Blindness & $\begin{array}{l}\text { Visual } \\
\text { impairment }\end{array}$ & $\begin{array}{c}\text { Uniocular } \\
\text { blindness }\end{array}$ \\
\hline Cataract & $4(19 \cdot 0 \%)$ & $41(68 \cdot 3 \%)$ & $18(37 \cdot 5 \%)$ \\
Onchocerciasis & $10(47 \cdot 6 \%)$ & $8(13 \cdot 3 \%)$ & $5(10 \cdot 4 \%)$ \\
$\quad$ anterior segment & 3 & 1 & 1 \\
$\begin{array}{l}\text { posterior segment } \\
\text { both segments }\end{array}$ & 1 & 5 & 3 \\
Glaucoma & $2(9 \cdot 5 \%)$ & $3(5 \cdot 0 \%)$ & $1(2 \cdot 1 \%)$ \\
Corneal opacity & $3(14 \cdot 3 \%)$ & $3(5 \cdot 0 \%)$ & $17(35 \cdot 4 \%)$ \\
(including phthisis bulbi) & 0 & $1(1 \cdot 6 \%)$ & $4(8 \cdot 3 \%)$ \\
Uveitis & $2(9 \cdot 5 \%)$ & $4(6 \cdot 7 \%)$ & $3(6 \cdot 3 \%)$ \\
Other & 21 & 60 & 48 \\
\hline
\end{tabular}

impairment in five individuals and was found in association with advanced blinding anterior and posterior segment onchocercal disease in a further 11 . Visual loss (less than $6 / 18$ vision) from glaucoma, either as a primary disease or complicating onchocercal eye disease, was found in $1 \%$ of the study population (16 individuals). Gonioscopy was performed on the 11 with advanced onchocercal disease and glaucoma. In 10 eyes the angle was not visible because of corneal oedema or sclerosing keratitis, two eyes had open angles, and in six eyes there were varying degrees of angle closure, ranging from multiple peripheral anterior synechiae through to angles completely closed by extensive anterior synechiae. Gonioscopy was not possible in four eyes.

Corneal opacity and phthisis bulbi were major causes of uniocular blindness, but were only infrequent causes of bilateral blindness or visual impairment.

\section{Discussion}

This study, conducted on a rural population in the southern province of Sierra Leone where onchocerciasis is hyperendemic, cannot be taken as representative of the whole country. Communities were initially selected for study because onchocerciasis was hyperendemic in the area and so the findings may not reflect the actual prevalences of ocular disease in the Tabe river valley. However, this study does give some information on the magnitude and causes of visual loss in similar communities. Blindness was found in $1 \cdot 3 \%$, visual impairment in $4.3 \%$ and uniocular blindness in a further $3.4 \%$ of the population who could be assessed. Children under the age of 1 year were not included in the study population and children in whom visual acuity could not be measured were excluded from the prevalence of visual impairment and uniocular blindness calculations, so that these figures are likely to overestimate the true total population prevalences. If it is assumed that all 225 children in whom visual acuity could not be measured actually had normal vision in both eyes, then the prevalence of visual impairment would be $3.7 \%$ $(60 / 1625)$ and uniocular blindness $3.0 \%$ (48/1625). These are therefore minimum estimates for people aged 1 year or over.

Visual field assessment was not possible in this study. Cases of peripheral field loss with preservation of central acuity, as seen characteristically with optic atrophy secondary to onchocerciasis, were therefore not detected.

Results of population based surveys of blindness in Africa show the prevalence to range from $0 \cdot 3 \%$ to $2 \cdot 3^{7-9}$ (Table 3 ), with cataract being the commonest cause. Community based surveys, undertaken in selected areas, show that in some localities onchocerciasis overtakes cataract as the leading cause of blindness. ${ }^{70}$ In our study cataract and onchocercal eye disease accounted for $78 \%$ of visual loss. This is similar to data from the northern savanna region of Sierra Leone. ${ }^{10}$

Cataract caused visual loss in $2 \cdot 8 \%$ of the study population and uniocular blindness in a further $1 \cdot 1 \%$. Extrapolating from this study to the country as a whole, about 10000 people are blind from cataracts and a further 45000 have 
Figure 1 Anterior segment signs of long standing onchocerciasis include $(A)$ sclerosing keratitis, and $(B)$ 'pseudohypopyon' secondary to chronic uveitis with a highly meiosed downdrawn pupil.

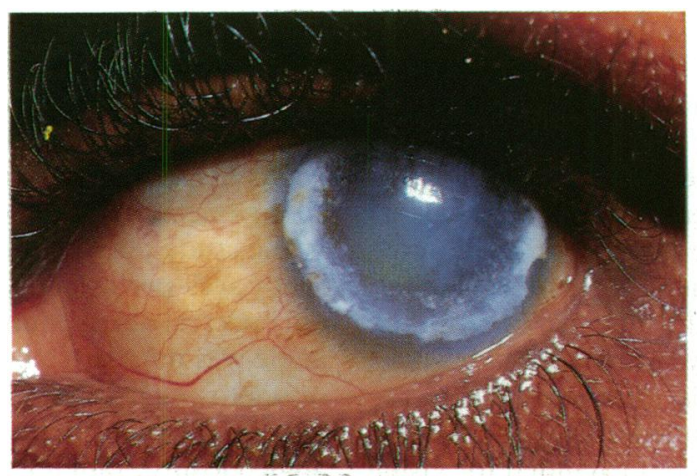

Fig $1 A$

blinding cataract in one eye. It is estimated that 2500 cataract operations are performed annually in Sierra Leone. To deal with the problem of blindness from cataracts more surgeons are required. Possible solutions include training medical practitioners or ophthalmic assistants to perform cataract surgery. Sierra Leone is just starting to train doctors, but at present there is no training for ophthalmologists within the country. (A two year diploma course in ophthalmology is to be initiated by the West African College of Surgeons in the next few years which could be used to train Sierra Leonean doctors for eye care and cataract services.)

Onchocerciasis accounted for visual loss in $1 \cdot 1 \%$ of this population. Recent results from trials have shown that ivermectin is a safe and effective microfilaricidal drug. " It reduces anterior segment disease, ${ }^{12}$ but the effect on posterior segment changes is still being evaluated. ${ }^{1314}$ The manufacturers (Merck Sharp and Dohme) have made ivermectin available free of charge, but there are considerable cost and manpower implications of distributing the drug on a regular basis to isolated communities. Control of the vector, Simulium damnosum, by regular larviciding of breeding sites, as carried out in West Africa by the Onchocerciasis Control Programme of WHO, has favourably influenced the prevalence of blindness, ${ }^{15}$ but requires substantial financial and logistic input.

Glaucoma was associated with visual loss in $1 \%$ of the study population. In the majority (11/16) this was found in association with severe onchocercal disease, an observation that has been previously reported. ${ }^{16}$ The frequent gonioscopy findings of extensive peripheral anterior synechiae suggest that the mechanism is one of chronic angle closure, presumably secondary to chronic anterior uveitis. Primary glaucoma accounted for visual loss (less than $6 / 18$ vision) in $0.3 \%$.

Levels of uniocular blindness were comparable with previous studies, ${ }^{81718}$ cataract and corneal damage accounting for most cases. Minor trauma, conjunctivitis, childhood measles, and the use of harmful eye practices including traditional medicines are probably important and preventable causes of corneal damage in this area, while xerophthalmia and trachoma were not observed.

More than $50 \%$ of all cases of visual loss in this study were treatable or preventable. The most important health measures to reduce visual loss in southern Sierra Leone are: the provision of

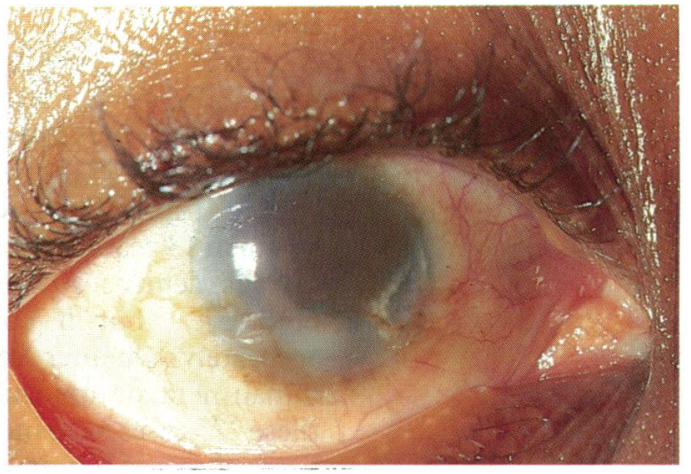

Fig $1 B$

cataract surgery and spectacles, the distribution of ivermectin in areas where onchocerciasis is hyperendemic, health education regarding harmful ocular practices, the promotion of childhood vaccination programmes, and making available safe treatment such as tetracycline eye ointment for infections. Any planned provision of ophthalmic care needs to concentrate on these basic public health and curative measures, and to provide a service that is accessible and acceptable to the majority of the rural population.

We thank the villagers in the study area, the staff at the Medica Research Council laboratory in $\mathrm{Bo}$, and the Sierra Leone Ministry of Health for their cooperation and help.

1 Clark JI. Sierra Leone in maps. 2nd ed. London: Hodder and Stoughton, 1969.

2 Manson-Bahr PEC, Bell DR, eds. Manson's tropical diseases. 19th ed. London: Balliere-Tindall, 1987.

3 Post RJ, Crosskey RW. The distribution of the Simulium damnosum complex in Sierra Leone and its relation to onchocerciasis. Ann Trop Med Parasit 1985; 79: 169-94.

4 Whitworth JAG, Morgan D, Maude GH, Downham MD, Taylor DW. A community trial of ivermectin for onchocer ciasis in Sierra Leone: clinical and parasitological responses to the initial dose. Trans $R$ Soc Trop Med Hyg 1991; 85: 92-6.

5 McMahon JE, Davies JB, White MD, Goddard JM, BeechGarwood PA, Kirkwood BR. Onchocerciasis in Sierr Leone. 1: Studies on the prevalence and transmission at Gbaiima village. Trans $R$ Soc Trop Med Hyg 1986; 80: 802-9.

6 World Health Organisation Programme for the Prevention of Blindness. Eye examination record, version III Unpublished mimeographed document. Geneva: WHO
1988; WHO/PBL/88.1.

7 World Health Organisation Programme for the Prevention of Blindness. Available data on blindness (update 1987) Unpublished mimeographed document. Geneva: WHO

1987; WHO/PBL/87.14.
$8 \mathrm{Faal} \mathrm{H,} \mathrm{Minassian} \mathrm{D,} \mathrm{Sowa} \mathrm{S,} \mathrm{Foster} \mathrm{A.} \mathrm{National} \mathrm{survey} \mathrm{of}$ blindness and low vision in the Gambia: Results. Br F Ophthalmol 1989; 73: 82-7.

9 World Health Organisation. Blindness prevention: prevalence and causes of blindness and visual loss. Whly Epidem Rec 1990; 65: 249-51.

10 Stilma JS, Bridger S. Causes and prevalence of blindness in the northern province of Sierra Leone. Doc Ophthalmol 1983; 56: 115-22.

11 Brown KR, Neu DC. Ivermectin - clinical trials and treatmen schedules in onchocerciasis. Acta Leidensia 1990; 59: schedules
$169-75$.

12 Taylor HR. Ivermectin treatment of ocular onchocerciasis. Acta Leidensia 1990; 59: 201-6.

13 Semba RD, Murphy RP, Newland HS, Awadzi K, Greene $\mathrm{BM}$, Taylor $\mathrm{H}$. Longitudinal study of lesions of the posterior segment in onchocerciasis. Ophthalmology 1990; 97 $1334-41$.

14 Whitworth JAG, Gilbert CE, Mabey DM, Maude GH, Morgan D, Taylor DW. The effects of repeated doses of ivermectin on ocular onchocerciasis - results from a community based trial in Sierra Leone. Lancet 1991; 338: munity

15 Dadzie KY, Rolland A, Thylefors B. The evolution of ocular onchocerciasis in the Volta river basin area over a period of five years of vector control. Tropenmed Parasit 1984; 35: five year

16 Thylefors B, Duppenthaler JL. Epidemiological aspects of intraocular pressure in an onchocerciasis endemic area. Bull WHO 1979; 57: 963-9.

17 Chirambo MC, Tielsch JM, West KP, Katz J, Tizazu T, Schwab $\mathrm{L}$, et al. Blindness and visual impairment in southern Malawi. Bull WHO 1986; 64: 567-72.

18 Ayanru JO. Blindness in the midwestern state of Nigeria Trop Geog Med 1974; 26: 325-32. 